\title{
Towards cleaner technologies: emissions reduction, energy and waste minimisation, industrial implementation
}

\author{
Igor Bulatov $\cdot$ Jiří Klemeš
}

Published online: 23 September 2008

(C) Springer-Verlag 2008

\begin{abstract}
This editorial introduces and provides an overview of a Special Issue dedicated to the jubilee 10th Conference of Process Integration, Modelling and Optimization for Energy Saving and Pollution ReductionPRES'07. It contains thirteen selected papers covering various fields of cleaner technologies and environment policy problems. The technologies address recent developments in $\mathrm{CO}_{2}$ capture in Combined Cycle power plants, $\mathrm{CO}_{2}$ reduction in pulp and paper mills, process efficiency increases combined with energy savings at a mill, distillation separation enhancements and emissions control at gas plants, pre-combustion decarbonisation for polygenertion from fossil fuels, minimisation of $\mathrm{CO}_{2}$ emissions in steam and power plants, a study of co-pyrolysis of biomass and plastic wastes, waste-to-energy system design (with a focus on incineration and gasification technologies), optimal design of wastewater treatment systems, and integrated production of sugar and biofuels from sugar beet. Among these topics, The Special Issue includes demonstration of the technologies in the form of Advanced Case studies.
\end{abstract}

\footnotetext{
I. Bulatov ( $\bowtie)$

Centre for Process Integration, CEAS,

The University of Manchester,

P.O. Box 88, Manchester M60 1QD, UK

e-mail: igor.bulatov@manchester.ac.uk

J. Klemeš

EC Marie Curie Chair (EXC) INEMAGLOW,

Faculty of Information Technology, Research Institute

of Chemical Technology and Process Engineering,

University of Pannonia, Egyetem ut. 10,

8200 Veszprém, Hungary

e-mail: klemes@cpi.uni-pannon.hu
}

\section{Introduction}

The issues of global warming and greenhouse gas emissions are increasingly becoming one of the major technological, as well as and also important societal and political challenges. They are closely related to energy generation and exploitation. The problem is becoming an increasingly urgent and consequently various conferences are being held to encourage closer collaboration among researchers of many nations.

The series of conferences on "Process Integration, Modelling and Optimisation for Energy Saving and Pollution Reduction" (PRES) is one such opportunity for close collaboration and the initiation of new ideas, projects and working relations. The Conference was established originally to address issues relevant to process energy integration in connection with the thermal efficiency of a range of processing units and processes. However, it has now been expanded to focus on the wider field of energy and pollution related issues. The organizers of the PRES conferences are proud to continuously attract delegates from many countries world-wide providing a genuine platform for the fast and efficient transfer of novel ideas, processes, procedures, policies and especially close working friendships.

This is the second Special Issue of Clean Technologies and Environmental Policy devoted to this theme. The previous issue was based upon documents submitted to the PRES 2006 conference and was published recently (Klemeš and Bulatov 2008). The PRES conference is also collaborating with several other well known journals, for example (Stehlík and Klemeš 2008, Klemeš et al. 2007, Klemeš and Friedler 2008, Klemeš and Pierucci 2008). The recently established collaboration with Clean Technologies and Environmental Policy is mutually greatly appreciated. 
The conference was organized in close collaboration with the Associazione Italiana Di Ingegneria Chimica as a joint event with the 8th Italian conference of Chemical Engineering ICheaP-8. The conferences were held on the beautiful Isle of Ischia (the twin island of Capri) in the Gulf of Naples.

\section{Overview of the papers included in this Special Issue: main thematic groups}

For this Special Issue of Clean Technologies and Environmental Policy, thirteen research papers representing interesting aspects of this field and related inputs are included. The international character of PRES is reflected by the fact that researchers from six European countriesSweden, France, Italy, Norway, Portugal and Czech Republic_-were competitively selected along with contributions from Latin America and Africa-Argentina and Libya.

The first section of this Special Issue includes the papers covering different aspects of emissions reduction in different processes: in a combined cycle power plant, in pulp and paper mills, energy savings combined with enhanced productivity of lignin extraction, and in polygeneration from fossil fuels, $\mathrm{SO}_{\mathrm{X}}$ emissions reduction. The second section is dedicated to energy saving and waste minimization: rigorous optimization of heat-integrated and Petlyuk column configurations based on feed conditions, a methodology for the optimal design of wastewater treatment systems, and analysis of an efficient waste-to-energy system as a component of cleaner technologies. The third section covers three case studies: conventional distillation configurations, description of a new proposal on integrated production of sugar and biofuels from sugar beet and copyrolysis of biomass and plastic waste.

\section{Emissions reduction}

The first paper in this section "Minimization of life cycle $\mathrm{CO}_{2}$ emissions in steam and power plants" (Martinez and Eliceche 2008) by Pablo Martinez and Ana Eliceche from Universidad Nacional del Sur, Argentina, describes a methodology to minimize life cycle $\mathrm{CO}_{2}$ emissions through the selection of the operating conditions of a steam and power generation plant. The authors extended the battery limits of the utility plant. They correctly included $\mathrm{CO}_{2}$ emissions of extraction and transport of natural gas burned in its boilers, generation of imported electricity by nuclear, hydroelectric and thermoelectric plants and exploration, extraction and transport of natural gas, oil, coal and uranium consumed by thermoelectric and nuclear plants. The operating conditions of the utility plant were selected to minimize the life cycle $\mathrm{CO}_{2}$ emissions. They use continuous operating conditions as the temperature and pressure of the high, medium and low pressure steam headers and binary operating conditions to represent discrete decisions to select optional pumps drivers between electrical motors and steam turbines or whether some equipment is on or off. The authors formulated a Mixed Integer Nonlinear Programming problem and solve it using GAMS. The resulting significant reductions in life cycle $\mathrm{CO}_{2}$ emissions, natural gas consumption and operating cost were achieved simultaneously in the steam and power generation system of an ethylene plant. The suggested approach was a support decision making tool to reduce $\mathrm{CO}_{2}$ emissions in this key industrial sector.

The second paper presents the possibilities of decarbonization in integrated pulp and paper mills. The authors Erik Hektor and Thore Berntsson from Chalmers University of Technology, Sweden, titled their paper "Reduction of Greenhouse Gases in Integrated Pulp and Paper MillsPossibilities for $\mathrm{CO}_{2}$ Capture and Storage" (Hektor and Berntsson 2008). Their earlier work has shown that capturing the $\mathrm{CO}_{2}$ from flue gases in the recovery boiler at a market pulp mill can be a cost-effective way of reducing $\mathrm{CO}_{2}$ emissions. They investigated whether it is valid for an integrated pulp and paper mill. They have compared five configurations, supplying the extra energy needed by a biofuel boiler, an NGCC, a heat pump, or by reducing the steam demand at the mill in combination with a biofuel boiler or an NGCC. The authors evaluated configurations within energy market scenarios and calculated the avoidance costs. Their research has shown that NGCC configurations have the lowest avoidance costs in all scenarios. There is also the advantage of liberating biofuel for use in other parts of society.

The third paper in this section deals with natural gas reforming technology. The title of the paper is "Reforming Natural Gas for $\mathrm{CO}_{2}$ Pre-Combustion Capture in Combined Cycle Power Plant" (Amann et al. 2008) and the authors are Jean-Marc Amann and Chakib Bouallou from Centre Énergétique et Procédés (CEP), Ecole Nationale Supérieure des Mines de Paris and Mohamed Kanniche from EDF, Research and Development Division, France. The researchers are assessing the conversion of a Natural Gas Combined Cycle power plant (NGCC) which uses an advanced gas turbine (GE9H) for $\mathrm{CO}_{2}$ pre-combustion capture. The natural gas is reformed in an auto-thermal reformer either with pure oxygen or with air. After watershift conversion of $\mathrm{CO}$ into $\mathrm{CO}_{2}$ and physical $\mathrm{CO}_{2}$ recovery, the synthesis gas contains a high fraction of $\mathrm{H}_{2}$, which is then diluted with $\mathrm{N}_{2}$ and steam to lower its low heating value (LHV) for $\mathrm{NO}_{\mathrm{X}}$ emission control. The study shows that oxygen purity and reforming pressure have little impact on performance, while high pressure reforming is 
preferred to reduce the process size. Using air reforming results into a slightly higher efficiency but a larger process. The $\mathrm{CO}_{2}$ recovery rate has a significant impact on the power plant efficiency as a large amount of steam is required to LHV of the synthesis gas leaving the recovery process. Two values of LHV were assessed. Steam consumption for natural gas reforming and synthesis gas dilution are the main consuming elements.

Another interesting decarbonization application is analyzed in "Assessment of Pre-combustion Decarbonisation Schemes for Polygeneration from Fossil Fuels" (Hetland 2008) a paper by Jens Hetland, SINTEF Energy Research from Norway. Emerging polygeneration schemes are now being actively investigated. They can apply pre-combustion decarbonization of fossil fuels, eventually with options for geological storage of the $\mathrm{CO}_{2}$. Those schemes are highly complex and they may require new approaches and knowledge on interactions between key components in large plants. New technologies and features are expected to occur in due course as the experience from polygeneration matures. The author refers to the European DYNAMIS project and the Sino-European $\mathrm{COACH}$ project, both conducted with the financial support of the European Community.

Due to increases in energy consumption, natural gas energy is becoming one of the most important sources to fulfill the world energy demand. But normally the available raw natural gas is mixed with some heavy components such as $\mathrm{C}_{3+}$ and/or some impurities such as $\mathrm{CO}_{2}, \mathrm{~N}_{2}$ and sulphur compounds $\left(\mathrm{H}_{2} \mathrm{~S}\right.$ and $\left.\mathrm{RSH}\right)$. The raw gas should therefore be treated to meet the international specifications and eliminate or at least minimize the emission of toxic and/or pollutant gases to the surrounding area. The next paper in this group describes the SOx emission and pollution control measures at Mellitah gas plant. The authors of "SOx Emission and Pollution Control at Mellitah Gas Plant" (Hasan et al. 2008) paper, Mohamed Hasan, Western Libya Gas Project-Mellitah Gas B. V. Libyan Branch, A Gambri, Mellitah Gas B. V. Libyan Branch, Adel Shiban, Oil Refining Co and M Abukshim, 7th of April University, Libya, present a process at the Mellitah site in which clean natural gas for export is produced and 99.8\% wt of associated sulphur compound with the raw gas and/or acid gas is recovered. The recovered sulphur is produced in liquid phase then dried for storage in the solid phase. The solid sulphur is exported to international market. The emission control at the Mellitah plant was optimized and controlled as per latest available technology. The fuel gas utilized for all the process is a completely clean gas; flue gas contains always less than $10 \mathrm{ppm}$ of $\mathrm{H}_{2} \mathrm{~S}$.

As a consequence the burned gas produced mainly $\mathrm{CO}_{2}$ and $\mathrm{H}_{2} \mathrm{O}$ with a trace amount of $\mathrm{SO}_{\mathrm{X}}$. The authors compare $\mathrm{SO}_{\mathrm{X}}$ emissions at the Mellitah with any other industrial complex in Libya or any other similar plant elsewhere utilizing fuel oil and/or diesel oil and come to conclusion that the Mellitah emissions are the lowest.

As decarbonization goes hand in hand with energy saving, we have included the paper "Energy Savings Combined with Lignin Extraction for Production Increase: Case Study at a Eucalyptus Mill in Portugal" (Laaksometsä et al. 2008) by Catherine Laaksometsä, Erik Axelsson, Thore Berntsson and Anders Lundström from Chalmers University of Technology, Sweden, into this section. The authors analyzed energy savings combined with lignin extraction as a means to debottleneck the recovery boiler evaluated on a model mill. The study showed that this concept was an efficient alternative to the upgrade of the recovery boiler. In this contribution they had taken a step further by investigating the potential for energy savings and possibilities for lignin extraction at a real pulp mill in Portugal. In this paper, they show that the energy-saving methods proved to be applicable also to the real mill and the steam-saving potential is $4.2 \mathrm{GJ} / \mathrm{ADt}$ or $33 \%$. Lignin extraction trials with bench scale equipment showed that lignin extraction was fully viable at the studied mill. A full-scale lignin separation plant according to the LignoBoost concept, combined with energy savings, was simulated in a computer environment and compared to installation of a new recovery boiler. A new recovery boiler had an investment cost four times higher than the LignoBoost concept combined with energy savings, although the electricity production would be higher. The profitability for a production increase of $16 \%$ was calculated for both cases. Steam savings combined with LignoBoost have better profitability unless electricity prices are very big, which is very likely going to happen in the near future.

The last paper in this section provides an example of how gasification can be used for processing wastes in a waste-to-energy system. The authors Radek Dvořák, Tomáš Pařízek, Ladislav Bébar and Petr Stehlík from Brno University of Technology, Institute of Process and Environmental Engineering VUT-UPEI, Brno, capital of Moravia Region in the Czech Republic. Their paper "Incineration and Gasification Technologies Completed with Up-to-Date Off-Gas Cleaning System for Meeting Environmental Limits" (Dvořák et al. 2008) analyzed incineration of waste taking into account environmental limits. This analysis is aimed at a typical arrangement of a conventional oxidizing incineration plant consisting of waste storage and feeding systems, two-stage incinerator (primary and secondary combustion chambers), and a heat recovery system involving cogeneration and off-gas cleaning system. They also considered a new arrangement where the primary combustion chamber (rotary kiln) is substituted by a gasification reactor. Experiments provided various important characteristics: heat value of produced 
syngas versus temperature in the gasification reactor, temperature in the secondary combustion chamber versus oxygen concentration in outlet flue gas and heat value of syngas, etc. It then becomes possible to make a comparison of conventional incineration and gasification process for a particular industrial process involving a unit for thermal treatment of hazardous industrial waste mixed with municipal solid wastes with capacity of $10,000 \mathrm{t} /$ year. An application of gasification technology which brings a whole range of benefits like minimizing the consumption of auxiliary fuel and decreasing the size of the secondary combustion chamber and other subsystems of the incineration plants was outlined.

Energy saving and waste minimization

The next group of papers deals with energy saving and waste minimization issues. The first paper analyses heatintegrated and Petlyuk column configurations and is titled "Rigorous Optimization of Heat-integrated and Petlyuk Column Distillation Configurations Based on Feed Conditions" (Kalifa and Emtir 2008). The authors are Mansour Khalifa and Mansour Emtir from the Libyan Petroleum Institute. The authors studied the steady-state design and rigorous simulation of several energy-integrated configurations compared to conventional distillation configurations for ternary mixture separation. The configurations were rigorously optimized based on the total annual cost as the economic objective function. The energy-integrated distillation configurations were compared with conventional configurations to find the maximum achievable total annual cost savings. Changing feed conditions was considered as one of the optimization variables by investigating different states of feed conditions; feed at temperature $15.5^{\circ} \mathrm{C}$, liquid at bubble point and vapor at dew point. The investigated configurations are conventional direct and indirect separation sequence, heat-integrated direct sequences, Petlyuk (Dived Wall Column) column, heat-integrated and double heat-integrated sloppy sequences. The optimization results indicated that savings in energy and total annual cost of the configurations is affected by the states of the feed conditions.

The paper from Pedro Castro, João Teles and Augusto Novais from Instituto Nacional de Engenharia Tecnologia e Inovação, Portugal, is titled "LP-based Algorithm for the Optimal Design of Wastewater Treatment Systems" (Castro et al. 2008). This paper describes a new approach for the optimal design of distributed wastewater treatment networks with multiple contaminants. The suggested was a two-stage solution strategy. In the first stage, a decomposition method was applied that replaces the general nonlinear program (NLP) by a succession of linear programs, one for each treatment unit. In the second stage, the resulting network was used as a starting point for the solution of the general NLP by a local optimization solver. A specific substructure of the decomposition process was considered. It was assumed that the wastewater streams go through the treatment units in sequence. To consider all combinations, the two-stage solution strategy is applied as many times as the number of possible sequences. This allowed multiple and structurally different starting points, with increasing the probability of finding global optimal solutions. The authors discussed the results and showed that the proposed approach can find better solutions than other approaches reported in the literature. However, the suggested approach is more demanding computationally.

The last paper in this group is authored by Martin Pavlas, Michal Touš from Brno University of Technology, Institute of Process and Environmental Engineering VUTUPEI, the Czech Republic and is titled "Efficient Waste to Energy System as a Contribution to Clean Technologies". (Pavlas and Touš 2008). The paper deals with the efficient energy utilization of thermal processing of waste (waste-toenergy). The authors outlined that an up-to-date incineration plant is not only a waste disposal facility. The waste combustion (incineration) processes are accompanied by the release of large amounts of energy, that should be effectively utilized (e.g., steam production and its export to consumers, power generation, cogeneration). The main purpose of incineration, treating the waste includes also waste-to-energy systems substituting conventional power plants fired by fossil fuel. Consequently, they contribute to reducing global environmental problems. The authors evaluated an existing incineration plant and the results of the analysis are presented and discussed. The arrival of increasingly stricter environmental limits represents a driving force for retrofit. At the same time, maximum heat recovery and efficient energy utilization should be required. The paper provides an analysis of the influence of different operational modes (type of waste incinerated, combustion temperature, air-preheating, etc.) and lay-out of heat recovery system (e.g., cogeneration) on plant performance. The paper has contributed to the solution of the important problem of incineration plant efficiency: economical utilization of energy produced. The paper also provides examples of integration into existing energy systems.

Case studies and industrial applications

The third group of papers selected for this Special Issue considers some case studies. The paper presented by Mansour Emtir and Asma Etoumi from the Libyan Petroleum Institute "Enhancement of Conventional Distillation Configurations for Ternary Mixtures Separation" (Mansour and 
Etoumi 2008) analyzed sequences that lead to considerable reductions in flue gas emissions due to lower energy requirements and cost reductions. Rigorous simulations at steady-state were conducted for the separation of two different ternary mixtures by conventional distillation with direct and indirect separation sequence. To reduce the remixing effects in the first column, a sidedraw stream was introduced at peak point composition of middle component as transfer stream to the second column. An economic optimization for the conventional and improved configurations based on energy consumption and total annual cost (TAC) as the objective function was carried out. The results indicated that improvements of thermodynamic performance of both columns are achievable with the maximum TAC saving of $29 \%$ in case of indirect sequence and $19 \%$ for the direct sequence at low concentration of middle component. Improved conventional distillation sequences also show a significant reduction of flue gas emissions $\left(\mathrm{CO}_{2}, \mathrm{SO}_{\mathrm{X}}\right.$, and $\left.\mathrm{NO}_{\mathrm{X}}\right)$ which are generated by the combustion process of the utility systems.

The second paper in this group, "New Proposal for Integrated Production of Sugar and Biofuels from Sugar Beet" (Vaccari et al. 2008) by Giuseppe Vaccari and Elena Tamburini from University of Ferrara, Italy and Gianluigi Marchetti and Gustavo Lenzini from S.M.I srl., Italy, has been chosen because it opens a new market, biofuels, for the European and world sugar beet industry. The authors described in their paper how the problems related to the traditional technology of sugarbeet processing have became so overwhelming that the beet sector in Europe, and particularly in Italy, has been shocked. If the sugar beet industry wants to survive, it is necessary to decrease the production costs through a simplification of the technology, radical energy and water consumption reduction, the elimination of the solid, liquid and gaseous waste. The problems were addressed, among the others, by a European Project (TOSSIE, TOward Sustainable Sugar Industry in Europe) whose main objective was disseminating the results of the research obtained recently. The authors propose different solutions including the elimination of calcocarbonic purification process, the utilization of membrane technology and suggesting different processing schemes. Their recent innovation: the elimination of the diffusion process and a balanced production (along with the crystallized sugar) of biofuels. The preliminary results obtained in laboratory and in a pilot plant were presented and discussed.

Filipe Paradela, Filomena Pinto, Ibrahim Gulyurtlu and Isabel Cabrita from INETI-DEECA, Protugal and Nuno Lapa, UNL-FCT, GDEH-UbiA, Portugal, investigated the recovery of two types of waste by the process of pyrolysis. The results are described in their paper "Study of the Co-pyrolysis of Biomass and Plastic Wastes" (Paradela et al. 2008). The results showed that by adding a plastics mix the overall efficiency of the slow pyrolysis of pine could be improved. It was possible to achieve higher liquid yields and less solid product than in the traditional slow pyrolysis carbonization of biomass. The liquids obtained had heating values similar to that of heating fuel oil. The gas products had energy contents superior to the producer gas. The solid fractions obtained showed heating values higher than some coals. The study identified some typical products of fast biomass pyrolysis used as raw material in several industries. The study also investigated the effects of experimental conditions in products yield and composition. The list of parameters showed higher influence in ascending order: reaction time on gas product composition (increase of the alkane content) and on liquid composition (increase in aromatics content); reaction temperature on products yield (decrease of liquid yield with increase of solids and gases) and on gas product composition (increase in alkane content); initial pressure on liquid composition (increase in the aromatics content) and mainly the pine content of the initial mixture on products yield (increase of gas and solid yield with a decrease in liquids) and on the gas product composition (favoring $\mathrm{CO}$ and $\mathrm{CO}_{2}$ formation).

\section{Conclusions}

We believe that the papers in this Special Issue of Clean Technologies and Environmental Policy will be of interest and relevant to a wide range of readers in sustainability and will bring the PRES Conference series to their attention. The help of all collaborators and especially the ISC members (PRES 2007) is gratefully acknowledged both for actively contributing to the conference and for taking part in the editorial process. We especially appreciate the contribution and help of all the authors. We would like to continue and further develop the mutual collaboration between the Clean Technologies and Environmental Policy and the PRES conference series. The eleventh PRES 2008 conference was held in Prague, the Czech Republic, jointly with CHISA 2008. Another Special Issue has been planned to be published in Clean Technologies and Environmental Policy.

\section{References}

Amann JM, Kanniche M, Bouallou C (2008) Reforming natural gas for $\mathrm{CO}_{2}$ pre-combustion capture in combined cycle power plant, Clean Technol Environ Policy. doi:10.1007/s10098-008-0167-2

Castro P, Teles J, Novais A (2008) LP-based algorithm for the optimal design of wastewater treatment systems. Clean Technol Environ Policy. doi:10.1007/s10098-008-0172-5 
Dvořák R, Pařízek P, Bébar L, Stehlík P (2008) Incineration and gasification technologies completed with up-to-date off-gas cleaning system for meeting environmental limits. Clean Technol Environ Policy. doi:10.1007/s10098-008-0170-7

Hasan M, Gambri A, Shibani A, Abukshim M (2008) SOx emission and pollution control at mellitah gas plant. Clean Technol Environ Policy. doi:10.1007/s10098-008-0168-1

Hektor E, Berntsson T (2008) Reduction of greenhouse gases in integrated pulp and paper mills - possibilities for $\mathrm{CO} 2$ capture and storage. Clean Technol Environ Policy. doi:10.1007/ s10098-008-0166-3

Hetland J (2008) Assessment of pre-combustion decarbonisation schemes for polygeneration from fossil fuels. Clean Technol Environ Policy. doi:10.1007/s10098-008-0178-z

Kalifa, Emtir (2008) Rigorous optimization of heat-integrated and Petlyuk column distillation configurations based on feed conditions. Clean Technol Environ Policy. doi:10.1007/s10098008-0171-6

Klemeš J, Bulatov I (2008) Editorial. Clean Technol Environ Policy 10(2):107-110

Klemeš J, Friedler F (2008) PRES 2006-energy resources and management: heat integration, heat pumps, emissions and waste to energy. Energy 33(6):837-841

Klemeš J, Pierucci S (2008) Emission reduction by process intensification, integration, P-Graphs, Micro CHP, heat pumps and advanced case studies. Appl Therm Eng doi: 10.1016/j.applthermaleng. 2008.06.010
Klemeš J, Pierucci S, Worrell E (2007) Sustainable processes thorough LCA, process integration and optimal design. Resour Conserv Recycl 50(2):115-121

Laaksometsä A, Axelsson E, Berntsson T, Lundström A (2008) Energy savings combined with lignin extraction for production increase: case study at a Eucalyptus mill in Portugal. Clean Technol Environ Policy. doi:10.1007/s10098-008-0169-0

Mansour E, Etoumi A (2008) Enhancement of conventional distillation configurations for ternary mixtures separation. Clean Technol Environ Policy. doi:10.1007/s10098-008-0174-3

Martinez P, Eliceche A (2008) Minimization of life cycle $\mathrm{CO}_{2}$ emissions in steam and power plants. Clean Technol Environ Policy. doi:10.1007/s10098-008-0165-4

Paradela F, Pinto F, Gulyurtlu I, Cabrita I, Lapa N (2008) Study of the co-pyrolysis of biomass and plastic wastes. Clean Technol Environ Policy. doi:10.1007/s10098-008-0176-1

Pavlas M, Touš M (2008) Efficient waste to energy system as a contribution to clean technologies. Clean Technol Environ Policy. doi:10.1007/s10098-008-0173-4

Stehlík P, Klemeš J (2008) Achievements in applied heat transferPRES (2006). Heat Transf Eng 29(6):503-505

Vaccari G, Marchetti G, Lenzini G, Tamburini E (2008) New proposal for integrated production of sugar and biofuels from sugar beet. Clean Technol Environ Policy. doi:10.1007/s10098008-0175-2

PRES'07 conference webiste, http://www.conferencepres.com, visited $06 / 07 / 2008$ 